\title{
Retraction Note to: Monitoring, analyzing and estimation of drought rate using new fuzzy index in cities of west and southwest of Iran, located in the north of the Persian gulf
}

\author{
Vahid Safarianzengir ${ }^{1} \cdot$ Behrouz Sobhani $^{1} \cdot$ Aghil Madadi $^{1}$. \\ Mohammadhasan Yazdani ${ }^{1}$
}

Published online: 24 August 2021

(c) Springer Nature B.V. 2021

\section{Retraction Note to: Environment, Development and Sustainability (2021) 23:7454-7468 https://doi.org/10.1007/s10668-020-00925-5}

The Editors-in-Chief and Publisher have retracted this article because the validity of the content of this article cannot be verified. An investigation by the Publisher found evidence suggestive of attempts to subvert the peer review and publication system.

Vahid Safarianzengir, Behrouz Sobhani, Aghil Madadi and Mohammadhasan Yazdani do not agree with this retraction.

Publisher's Note Springer Nature remains neutral with regard to jurisdictional claims in published maps and institutional affiliations.

The original article can be found online at https://doi.org/10.1007/s10668-020-00925-5.

Behrouz Sobhani

behroz.sobhani@yahoo.com

Vahid Safarianzengir

Safariyan.vahid@gmail.con

Aghil Madadi

Aghil38madadi@yahoo.com

Mohammadhasan Yazdani

yazdani.m51@gmail.com

1 Department of Physical Geography, Climatology, Faculty of Literature and Humanities, University of Mohaghegh Ardabili, Ardabil, Iran 